\title{
Erratum to: Disseminated oligodendroglial-like leptomeningeal tumors: preliminary diagnostic and therapeutic results for a novel tumor entity
}

\author{
Matthias Preuss $^{1} \cdot$ Holger Christiansen ${ }^{2} \cdot$ Andreas Merkenschlager $^{3} \cdot$ \\ Franz Wolfgang Hirsch ${ }^{4}$ - Wieland Kiess ${ }^{5}$ - Wolf Müller ${ }^{6}$ • Stefanie Kästner ${ }^{7}$. \\ Andreas Henssler $^{8} \cdot$ Arnulf Pekrun $^{9} \cdot$ Holger Hauch $^{10} \cdot$ Michaela Nathrath $^{11}$. \\ Jürgen Meixensberger ${ }^{1} \cdot$ Torsten Pietsch $^{12} \cdot$ Klaus Kuchelmeister $^{12}$
}

Published online: 3 June 2015

(C) Springer Science+Business Media New York 2015

\section{Erratum to: J Neurooncol \\ DOI 10.1007/s11060-015-1735-z}

The original publication contains the following errors:

In the title, the words 'oligodendroglial cell-like' should read 'oligodendroglial-like'. (The correct title is shown in this erratum.)

The images in Figs. 3 and 4 were incorrect. The correct figures are shown below.
All the figure citations except the citation of Fig. 1 were incorrect. All citations of Fig. 2 actually concern Fig. 5, all citations of Fig. 3 actually concern Fig. 6, all citations of Fig. 4 actually concern Fig. 2, all citations of Fig. 5 actually concern Fig. 3 and all citations of Fig. 6 actually concern Fig. 4.
The online version of the original article can be found under doi:10.1007/s11060-015-1735-z.

Matthias Preuss

preuss@ neurosurgeon.ch

1 Department of Neurosurgery, University of Leipzig, Liebigstrasse 20, 04103 Leipzig, Germany

2 Division of Pediatric Oncology and Haematology, University of Leipzig, Leipzig, Germany

3 Division of Neuropediatrics, University of Leipzig, Leipzig, Germany

4 Department of Pediatric Radiology, University of Leipzig, Leipzig, Germany

5 Department of Children's and Adolescence Health, University of Leipzig, Leipzig, Germany

6 Institute of Neuropathology, University of Leipzig, Leipzig, Germany
7 Department of Neurosurgery, Klinikum Nordhessen GmbH, Kassel, Germany

8 Department of Neurosurgery, Klinikum Bremen-Mitte, Bremen, Germany

9 Department of Pediatric Hematology and Oncology, Klinikum Bremen-Mitte, Bremen, Germany

10 Department of Pediatric Hematology and Oncology, University of Gießen, Giessen, Germany

11 Department of Pediatric Hematology and Oncology, Klinikum Nordhessen GmbH, Kassel, Germany

12 Institute of Neuropathology, University of Bonn, Bonn, Germany 

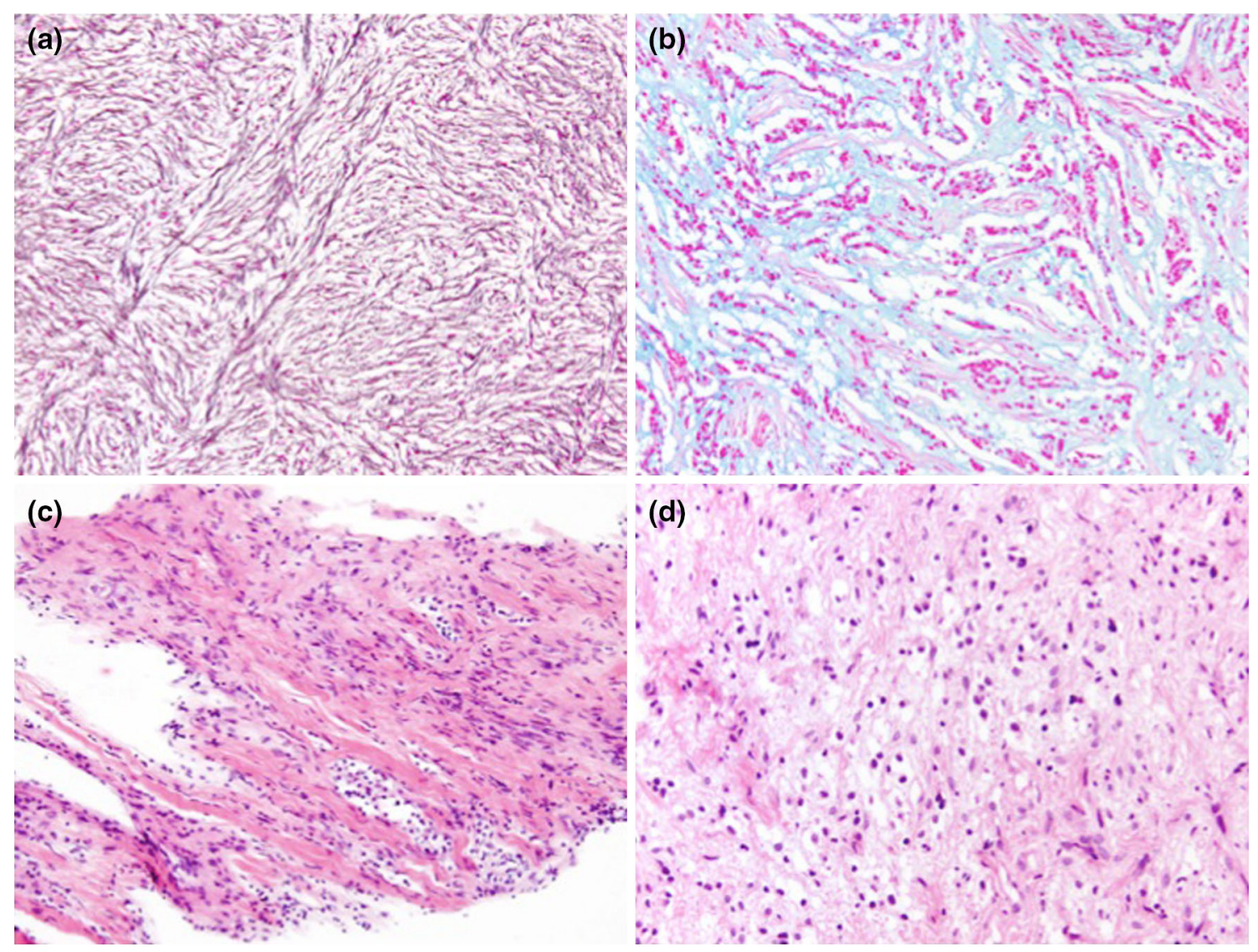

Fig. 3 a Case 2, first operation: desmoplastic fibrous tissue with a high reticulin fibre content and a focal storiform pattern (reticulin silver reaction). b Case 2, third operation: nests and rows of oligoid tumor cells in a strongly alcian blue-positive myxoid matrix (alcian

blue stain). c Case 4, first operation: oligodendroglial-like tumor cells showing a diffuse arrangement and cell nests and cell rows (H\&E). d Case 1: oligoid cells with perinuclear halos (H\&E) (original magnifications: $\mathbf{a}-\mathbf{c} \times 100, \mathbf{d} \times 200$ ) 


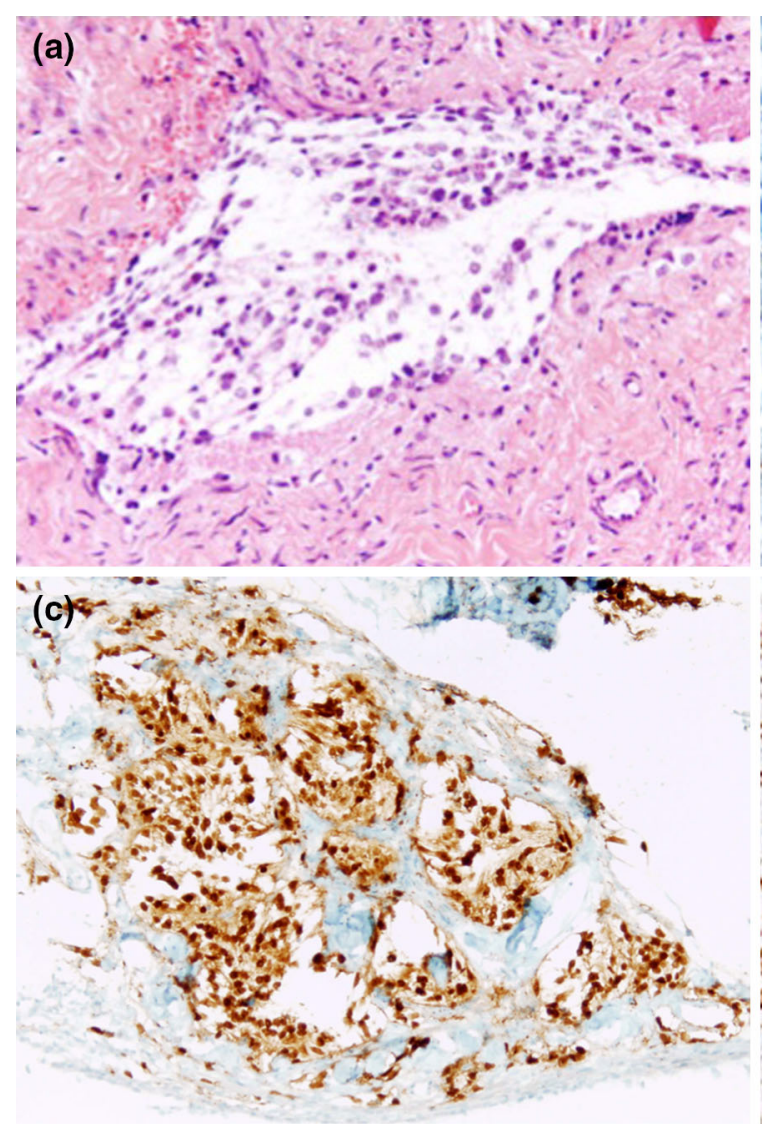

Fig. 4 a Case 4, second operation: tumor cells with round nuclei in a focal myxoid area sometimes show small cytoplasmic rims with processes (H\&E). b Case 2, second operation: oligoid tumor cells showing small MAP2-positive cytoplasmic rims (middle). On the right, adjacent Map2-positive brain tissue is seen (MAP2-immunohistochemistry). c Case 4, first operation: oligoid tumor cells display

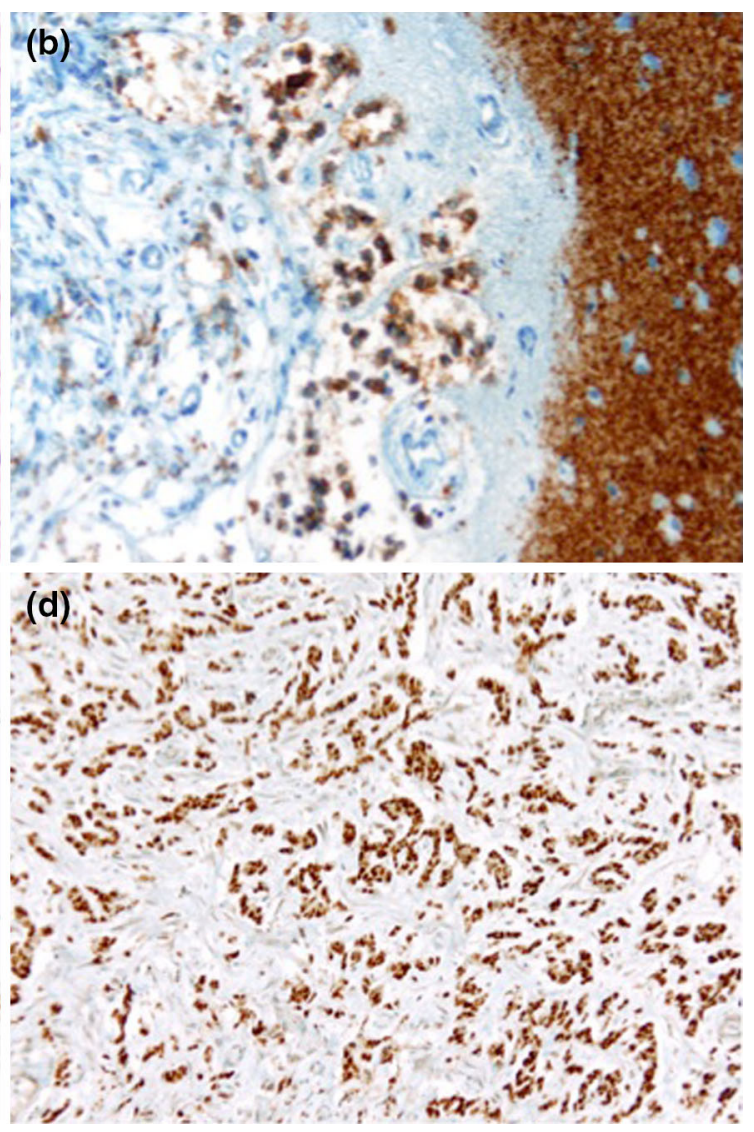

strong nuclear and sometimes also cytoplasmic S-100 proteinimmunopositivity (S-100 protein-immunohistochemistry). d Case 2, second operation: nuclear OLIG2-immunopositivity of the tumor cells (OLIG2-immunohistochemistry) (original magnifications: $\mathbf{a}-\mathbf{c} \times 200$, d $\times 100)$ 